\title{
Anticipating Primary School Students' Answers of Hierarchical Classifications Tasks: Features of Preservice Primary Teachers' Curricular Reasoning
}

\author{
Melania Bernabeu(i) \\ Mar Moreno $D^{\mathrm{a}}$ \\ Salvador Llinares (1Da \\ a Universidad de Alicante, Departamento de Innovación y Formación Didáctica, San Vicente del Raspeig, \\ España
}

Received for publication on 13 Oct 2021. Accepted after review on 2 Nov. 2021.

Designated editor: Claudia Lisete Oliveira Groenwald

\begin{abstract}
Background: Anticipating students' answers involves reasoning with knowledge from scientific domains supporting the practice of teaching mathematics and it is an evidence of preservice teachers' reasoning curricular. A key aspect in the geometrical thinking development is to understand the relationship between definition and classification of geometric objects. Thus, the way in which preservice teachers relate the definition and classification can provide information about their curricular reasoning. Objective: The aim of this study is to characterise how preservice teacher anticipate students' answers to hierarchical classification tasks of quadrilaterals and prisms. Design: The data collection instrument was a hierarchical classification task with four versions in which preservice teacher had to define geometric objects take into account some inclusion conditions. Setting and Participants: Twenty-eight preservice teacher from a university of Spain participated in this study. Data collection and analysis: The data was collected in two moments, firstly preservice teachers answered to the task with $2 \mathrm{D}$ figures and then to the $3 \mathrm{D}$ shapes. We carried out an inductive analysis through two phases take into account the specialization of definitions and transitivity of inclusion relationships. Results: We identified three profiles of the preservice teachers' curricular reasoning considering how they define the geometrical object considering the inclusion relations. Furthermore, some variability between the quadrilaterals and prisms was displayed considering curricular reasoning. Conclusions: The results under light the relationship between geometry knowledge and preservice teachers' curricular reasoning.

Keywords: Anticipating students' answers; Curricular noticing; Curricular reasoning; Hierarchical classification in geometrical tasks; Geometrical Thinking
\end{abstract}

Corresponding author: Melania Bernabeu. Email: melania.bernabeu@ua.es 


\section{Antecipação das respostas dos alunos do ensino primário às tarefas de classificação hierárquica: características de preservar o raciocínio curricular dos professores primários}

\section{RESUMO}

Antecedentes: Antecipar as respostas dos alunos envolve raciocínio com conhecimento de domínios científicos que apoiam a prática do ensino de matemática e é uma evidência do raciocínio curricular dos futuros professores. Um aspecto fundamental no desenvolvimento do pensamento geométrico é compreender a relação entre a definição e a classificação de objetos geométricos. Assim, a forma como os futuros professores relacionam a definição e a classificação pode fornecer informações sobre o seu raciocínio curricular. Objetivo: O objetivo deste estudo é caracterizar como o futuro professor antecipa as respostas dos alunos a tarefas de classificação hierárquica de quadriláteros e prismas. Design: O instrumento de coleta de dados foi uma tarefa de classificação hierárquica com quatro versões em que o futuro professor teve que definir os objetos geométricos levando em consideração algumas condições de inclusão. Cenário e participantes: Vinte e oito licenciandos de uma universidade da Espanha participaram deste estudo. Coleta e análise de dados: Os dados foram coletados em dois momentos, primeiro os futuros professores responderam à tarefa com figuras $2 \mathrm{D}$ e depois com as formas 3D. Realizamos uma análise indutiva em duas fases levando em consideração a especialização das definições e a transitividade das relações de inclusão. Resultados: Identificamos três perfis de raciocínio curricular dos licenciandos, considerando como eles definem o objeto geométrico considerando as relações de inclusão. Além disso, alguma variabilidade entre os quadriláteros e prismas foi exibida considerando o raciocínio curricular. Conclusões: Os resultados mostram a relação entre o conhecimento de geometria e o raciocínio curricular dos futuros professores.

Palavras-chave: Antecipação das respostas dos alunos; Olhar Curricular raciocínio curricular; classificação inclusiva; Pensamento geométrico.

\section{INTRODUCTION}

Some of the most challenging tasks in geometry teaching in primary education are related to the classification of geometric objects (de Villiers, 1994). Specifically, understanding a geometric object as an example of a class (hierarchical classification) is evidence of progression in geometric thinking. The hierarchical classification of geometric objects is based on the generation of conceptual relationships between the figures, not on their perceptual aspects, and involves a progression in the development of geometric thinking, for example, when considering the square as a particular case of rectangle or a cube as an example of a prism. From the perspective of the Van Hiele's levels of geometric thinking development (Van Hiele, 1986), the understanding of hierarchical classifications is placed at the relational level (level 3). The 
relational level is featured by the ability of students to infer relationships between the properties of the figures and make simple logical deductions. For example, assuming that the perpendicular diagonals in the parallelograms imply the congruence of the sides, or that the parallelograms have congruent opposite sides and angles.

The relationship between the perceptual character of geometric objects and the logical and conceptual conditions that govern the thought process is what Fischbein (1993) called the figural concept. The figural concept is conditioned by the mental images that students usually construct and by the difficulties in generating deductive processes using the attributes of the figures (Fujita 2012; Fujita \& Jones, 2007; Bernabeu et al, 2017). For instance, when students provide definitions of the geometric figures and shapes giving some attribute that can be derived from what has already been said (redundancy of the definitions), or because of the difficulties in understanding that by adding a condition to a geometric object one creates a subclass (generating an hierarchical relationship). Difficulties with hierarchical relationships have been described both in students of different educational levels and in preservice teachers.

The origin of these difficulties is linked to the conception of the hierarchical relationship between the figures. These relationships imply that a figure of class B has all the properties of class A in which it is included. In other words, to get an example of $\mathrm{B}$, we have added an attribute to the definition of A. For example, to consider an isosceles trapezium as a particular example of the set of trapeziums (quadrilaterals with at least two parallel sides) when adding to the definition of trapezium the condition of having congruent nonparallel sides; or a cube as a particular example of a right prism when defining a cube as a square-faced prism.

In this way, two inverse processes are generated when defining geometric figures and shapes. On the one hand, the specialization (de Villiers, 1994, pp. 13-14) process, by adding properties to the definition of geometric objects to obtain particular cases and, on the other hand, the generalization (de Villiers, 1994, pp. 13-14) process, by suppressing conditions from the definition of the geometric object to create a more general class. Understanding these two processes is based on identifying attributes and establishing relationships between them, which makes it possible to generate hierarchical classifications (de Villiers, 1994).

The information provided by previous research on the apprehension of quadrilateral and prism classifications (Brunheira \& da Ponte, 2019; Jones \& 
Tzekaki, 2016; Sinclair et al., 2016) indicates difficulties in defining and classifying geometric figures and shapes derived from the participants' little experience in the classification process and the role played by prototypical images. This situation raises questions about the relationship between defining and classifying when preservice teachers have to assess the potential of geometric tasks when planning their teaching and justifying them in relation to learning objectives.

\section{Anticipate students' response as an aspect of teachers' "curricular reasoning" in teaching planning}

A trait of teachers' teaching competency when planning teaching and justifying mathematical tasks is determined by the way they interact with curricular materials (Gueudet, 2019; Remillard, 2019); in particular, in recognising learning opportunities for students when solving tasks in a lesson plan. (Dietiker et al., 2018),

For that the preservice teachers can take advantage of mathematical learning opportunities from curriculum materials (assignments, resources, etc.), themselves must first recognise such opportunities. From this point of view, we attempt to characterise how preservice teachers reason with curricular materials. In particular, how they anticipate students' answers to the tasks included in a lesson. Dietiker and colleagues (2018) introduce the curricular noticing construct to describe a set of professional practices that allow teachers to recognise, interpret, and generate learning opportunities from curricular material as a way of reasoning with curricular materials. Curriculum noticing includes connecting the mathematics necessary to solve the tasks with the intended learning objectives (the expectations of curriculum achievement). In this way, reasoning with curricular materials requires teachers to mobilise math knowledge, knowledge about how students learn and knowledge about the characteristics of the tasks (what the task demands of the student). On the other hand, the term curricular reasoning has been defined as the thought processes in which teachers engage when working with curricular materials to plan, implement, and reflect on teaching (Breyfogle et al., 2012; Wilson et al., 1987).

A scope in which teachers reason about the tasks is when they think about the possible answers that students can give and how these answers reflect their mathematical understanding (Llinares, Fernandez, Sánchez-matamoros, 2016). That is, anticipating students' answers to tasks in a lesson is a skill linked to curricular reasoning (Curricular Noticing; Dietiker et al., 2018) as an aspect 
of professional noticing (Fernandez, Sánchez-matamoros, Valls and Callejo, 2018).

The way in which a preservice teacher reasons is exemplified when he/she identifies the mathematics content in the tasks anticipating possible answers. For example, faced with an activity of defining geometric figures that reflect an hierarchical relationship, preservice teachers must consider the way in which adding properties to the definition of a quadrilateral or prisms generates subclasses (the specialization of the definition) and the transitivity of the inclusion relationships (de Villiers, 1994) when more than two classes of geometric figures or shapes are related (if $\mathrm{A}->\mathrm{B}$, and $\mathrm{B}->\mathrm{C}$; then $\mathrm{A}->\mathrm{C}$ ). The processes of specialization of definitions and transitivity of hierarchical relationships are key in the understanding of the relationship between defining and classifying in primary education. The way in which preservice teachers use these two processes (the specialization of definitions and the transitivity of inclusion relationships) can provide us with information on how they reason curricularly in this specific domain of geometry teaching in primary education. To generate information about this situation, we ask the following research question:

How do preservice teachers anticipate correct answers to tasks of hierarchical relationships between quadrilaterals and between prisms as a skill linked to curricular noticing?

\section{METHODOLOGY}

\section{Participants and context}

The participants of this study were 28 preservice primary education teachers. The preservice teachers participated in a teaching experiment lasting eight hours and aimed at developing their professional noticing of primary students' geometric thinking and their curricular reasoning about the tasks, (four sessions of two hours each). The teaching experiment was based on the hypothesis that analysing and anticipating answers from primary school children helps to develop the preservice teachers' reasoning processes about students' mathematical thinking and about curricular materials.

During the sessions preservice teachers were introduced to the characteristics of primary students' geometrical thinking development. One specific focus was the relationship between the definitions and classifications of the geometric objects (geometric figures and shapes) and tasks in the lessons 
to support the students' understanding of this relationship. Specifically, considering the link between adding conditions to a figure to generate a subclass and, the inclusion relation that is established between the general class and the generated subclass. To this end, preservice teachers carried out three type of tasks: (i) analysed primary school students' answers to geometric tasks, (ii) anticipated students' answers to activities of classifying polygons and polyhedra, and (iii) analysed teaching tasks that aimed to promote the understanding of hierarchical relationships (Lehrer et al., 2014).

At the end of the teaching experiment, the preservice teachers answered a task that requested them to anticipate primary students' answers to an activity of classifying quadrilaterals. Four weeks later, they answered another task that requested them to anticipate primary students' answers to an activity of classifying prisms. These tasks were intended to reflect the understanding of preservice teachers of hierarchical relationships. In particular, characterise how preservice teachers understood the relationship between defining and classifying (Usiskin \& Griffin, 2008). The difference in data collection between quadrilateral and prism tasks was determined by the organisation of the course in which the teaching experiment was implemented.

\section{The tasks}

The tasks are contextualised in a lesson plan designed for students aged 10-12 years (Figure 1), with the following learning objective: Understand hierarchical relationships between geometric objects. This aim was focused on the relationship between the definition and classification (disjoint/partitive or hierarchical) of quadrilaterals and prisms.

The task of defining and classifying quadrilaterals had three versions, focused on the process of generating subclasses of quadrilaterals by adding conditions to the definitions of some quadrilaterals. The task of defining and classifying prisms had only one version (Figure 1). 


\section{Figure 1}

Task of anticipating primary students' answers to activities of defining with conditions

A primary school student, who is at level 3 of the development of geometric thinking, is presented with the following classification and is asked to define the geometric figures/shapes. Please, anticipate a possible correct answer. (The lines that join the labels mean from the bottom up: "it is an example of ...")

Geometric figures

\begin{tabular}{|c|c|c|c|}
\hline Version 1a: & Version $1 \mathrm{~b}$ : & Version 1c: & Version 1d: \\
\hline \multirow[t]{2}{*}{ TRAPEZIUM } & & QUADRILATERAL & \multirow[b]{2}{*}{ PRISM } \\
\hline & ROMBHOID & & \\
\hline ISOSCELES TRAPEZIUM & & KITE & \\
\hline & RHOMBUS & & \begin{tabular}{|l} 
PARALLELEPIPED \\
\end{tabular} \\
\hline RECTANGLE & & ROMBHUS & \multirow{3}{*}{ CUBE } \\
\hline & SQUARE & & \\
\hline SQUARE & & SQUARE & \\
\hline $\mathrm{N}=5$ & $\mathrm{~N}=12$ & $\mathrm{~N}=11$ & \multirow{2}{*}{$\mathrm{N}=28$} \\
\hline \multicolumn{3}{|c|}{$\mathrm{N}=28$} & \\
\hline
\end{tabular}

Anticipating correct answers highlights preservice teachers' curricular reasoning processes. In version 1a (Trapezium $\rightarrow$ Isosceles Trapezium $\rightarrow$ Rectangle $\rightarrow$ Square), considering the hierarchical relation between the given figures, the trapezium should be defined as a quadrilateral with at least two parallel sides. Next, if we add the condition that its diagonals are congruent, we get the isosceles trapezium. Suppose we add to this definition the condition of having all its angles congruent. In that case, we get the rectangle as a "quadrilateral with at least two parallel sides that has equal diagonals, with all angles congruent". Finally, if we add to this definition the condition of having all sides equal. In that case, we obtain the definition of a square (being, in this case, the square a particular case of the rectangle, the rectangle a particular case of the isosceles trapezium and, the isosceles trapezium a particular case of the trapezium).

In version $1 \mathrm{~b}$ (Rhomboid $\rightarrow$ Rhombus $\rightarrow$ Square), if the rhomboid is defined as a quadrilateral with parallel sides two by two. Then, we have a definition equivalent to parallelogram (this is necessary to consider the hierarchical relationships that the activity establishes) (Usiskin \& Griffin, 2008). If we add to this definition the condition that the four sides are congruent, we get the definition of "parallelogram with congruent sides", which we can call rhombus. Finally, if we add the condition that the four angles 
are congruent, we obtain the definition of square as a "parallelogram with congruent sides and angles" (being, in this way, the square a particular case of the rhombus and, the rhombus a particular case of the rhomboid)

In version 1c (Quadrilateral $\rightarrow$ Kite $\rightarrow$ Rhombus $\rightarrow$ Square), a quadrilateral is a polygon with four sides. If we add the condition that the diagonals are perpendicular with two pairs of congruent adjacent sides, we obtain the definition of kite as a particular case of quadrilaterals. Adding to the definition of a kite the condition that all its sides are congruent allows obtaining a definition of rhombus as "quadrilateral with perpendicular diagonals and congruent sides". Finally, by adding to this definition of rhombus the condition of having congruent angles or congruent diagonals obtain the definition of square as "a quadrilateral with perpendicular diagonals and congruent sides and angles".

It is noteworthy that some of the figures used in this task usually appear in the primary education curriculum with partitive (non-inclusive or nonhierarchical) definitions. For example, a kite is defined as a non-regular quadrilateral (trapezoid with two pairs of equal adjacent sides, the first pair being different from the second pair), or rhomboid as a parallelogram with two opposite angles that are acute and the other two angles are obtuse. Consequently, the task requested to the preservice teachers has a high cognitive demand since it requires overcoming the partitive definitions that may be associated with prototypical images when the logical conditions imposed by the task (add conditions) have to considered. Thus, the progressive process of adding conditions to the initial objects generates subclasses, establishing a relationship between the hierarchical relationships of geometric objects (transitivity), which the teachers must take into account.

In version 1d, about geometric shapes (Prisma $\rightarrow$ Parallelepiped $\rightarrow$ Cube), we can define prism as a polyhedron that has two parallel and equal faces, called bases, and its lateral faces are parallelograms. If we add the condition that the bases are parallelograms, we reach the definition of parallelepiped as a prism with all its faces are parallelograms. Finally, if we add to this definition the condition that all faces are square, then, we have the definition of cube as a prism in which all faces are square.

These tasks require to preservice teachers generate reasoning processes using knowledge of geometry and knowledge of students' geometrical thinking in primary education to anticipate students' answers. In this case, when they have to define different types of quadrilaterals and prisms with the conditions given by the hierarchical relationships in the task. In this type of task, the 
definitions of quadrilaterals and prisms that preservice teachers can provide, may be different, but they must be mathematically equivalent. This equivalence is supported by the relationships between the properties assigned to geometric objects. Namely, a rhomboid can be defined as a quadrilateral with congruent opposite sides two by two (or quadrilateral with congruent opposite angles two by two), which is equivalent to saying that it has parallel sides and, therefore, be a parallelogram.

\section{Analysis}

The tasks presented involve two conditions: defining geometric objects considering hierarchy conditions. Preservice teachers find it challenging to handle these two conditions at once as they may be more familiarized with defining geometric objects without conditions or using partitive definitions. For example, defining a rhombus as a parallelogram with congruent sides and angles, two by two, but different, and a square as a parallelogram with congruent sides and angles, generating disjoint sets. In the task provided, students had to consider when they could not use a partitive definition (which will generate disjoint sets) due to the hierarchical conditions imposed by the task. Thus, the objective of the analysis was to identify how the preservice teachers defined the geometric objects given, taking into account the indicated hierarchical relationships. The analysis process followed two phases.

In phase 1, (a) we identified the correct definitions, and then (b) to what extent the given definitions considered the indicated hierarchical relationships. These two steps allowed us to identify correct answers, those that correctly reflected the three hierarchical relationships between the definitions in tasks 1a and 1c; or reflected the two hierarchical relationships between the definitions in tasks $1 \mathrm{~b}$ and $1 \mathrm{~d}$.

In phase 2, we characterised the groups of students generated in the phase 1, considering how they reflected the processes of specialization/generalization of the definitions and the transitivity of the hierarchical relationships between the different geometric figures and shapes. For this, we took into account two criteria:

a) The specialization of the definitions, i.e., the extent to which the preservice teachers considered that it is possible to generate subclasses by adding attributes to the general class. For example, in task 1c, defining a rhombus as a quadrilateral with perpendicular diagonals and congruent sides, and then defining a 
square by adding to the definition of a rhombus the condition of having congruent angles. Or, on the contrary, the generalization of the definitions, i.e., when we obtain a more general class by suppressing a property from the subclass definition. For example, in task $1 \mathrm{~b}$, defining a square as a parallelogram with congruent angles and sides, and then defining a rhombus by suppressing the condition of the four angles are congruent (indicating only that are they are congruent two by two).

b) The transitivity of the hierarchical relationships (A then B, B then $\mathrm{C}$; so A then C). For example, when the given definitions allow seeing that, if a cube is a parallelepiped, and a parallelepiped is a prism, then the cube is a prism. In other words, the cube meets all the conditions of being a parallelepiped (but there are parallelepipeds that are not cubes), and that the parallelepipeds meet the conditions of being a prism (but there are prisms that are not parallelepipeds). This reflects the understanding of asymmetric relationships between the hierarchical relationships of geometric objects.

To perform the analysis, we proceeded as follows. First, we analysed the answers by identifying their correctness and how they considered the hierarchical relationships, comparing the answers, identifying similarities and differences (phase 1). Secondly, we interpreted the groups generated from the processes of specialization and transitivity (phase 2) considered as preservice primary teachers' profiles of the teaching competency to anticipate primary students' answers as a skill linked to Curricular Noticing.

During the process, we had to managed reasonable doubts arose from the way preservice teacher wrote their answers. For example, in task 1b, when student EM6 defines a square as a quadrilateral with four sides and four equal angles of $90^{\circ}$, we do not know if the term "equal" qualifies to sides and angles

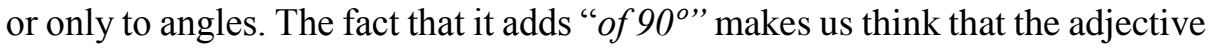
"equal" only refers to the angles (however, we can generate an alternative interpretation, considering that sides and angles are equal, but also that the measure of angles is $90^{\circ}$ ) Therefore, we could not differentiate a square from a rectangle; so, we consider it an incorrect definition (taking into account the hierarchical conditions of the task). Another example is when a preservice student defines incorrectly a figure that he is not being asked and then he uses the name of this new figure to define the figure that is being asked. In this case, although replacing the name of the additional figure by its definition results in 
a correct definition, this response has been considered incorrect, since it relies on an incorrect definition of the auxiliary figure used. For example, in task 1c, preservice teacher EM26 introduces the definition of a rectangle, which had not been requested, as a parallelogram with parallel sides 2 to 2 , which is incorrect. Next, he defines a rhombus as a rectangle with four equal sides. By replacing the term rectangle with the incorrect definition given, he generates a correct definition of a rhombus, a parallelogram with parallel sides two by two, with four equal sides. However, since it relies on an incorrect definition, it has been considered incorrect.

\section{RESULTS AND ANALYSES}

The analysis generated three preservice teachers' profiles, taking into account the process of specialization and generalization when defining quadrilaterals and prisms with the indicated hierarchical conditions (and, therefore, on the idea of the transitivity of the hierarchical relationships). These profiles are:

Profile 1. Without using the specialization process in the definitions.

Profile 2. Partial use of the specialization process in the definitions that entail the non-transitivity of the hierarchical relationships.

Profile 3. Use of the specialization process in the definitions that entail the transitivity of the hierarchical relationships.

Table 1 reflects the characteristics of the profiles identified considering the two conditions of the tasks (define, considering the hierarchical relationships) (phase 1 of the analysis) and how specialization/generalization and transitivity were considered (phase 2 of the analysis).

\section{Table 1}

Characteristics and frequencies of the preservice primary teachers' profiles of anticipating answers in tasks of defining geometric objects taking into account hierarchical relationships

\begin{tabular}{lllcccc}
\hline \multirow{2}{*}{ Profiles } & \multicolumn{1}{c}{ Characteristics } & \multicolumn{2}{c}{ Quadrilaterals } & \multicolumn{2}{c}{ Prisms } \\
& & 1a & 1b & 1c & 1d \\
\hline $\begin{array}{l}\text { Profile 1. Without using } \\
\text { the specialization process } \\
\text { in the definitions }\end{array}$ & $\begin{array}{l}\text { They do not recognise the } \\
\text { process of generating } \\
\text { subclasses: adding }\end{array}$ & 0 & 7 & 5 & 6 \\
& & & & & & \\
& & & & &
\end{tabular}




\begin{tabular}{|c|c|c|c|c|c|}
\hline & $\begin{array}{l}\text { properties to the figures of } \\
\text { a class generates a more } \\
\text { specific class (subclass) }\end{array}$ & & & & \\
\hline $\begin{array}{l}\text { Profile 2. Partial use of } \\
\text { the specialization process } \\
\text { in the definitions that } \\
\text { entail the non-transitivity } \\
\text { of the hierarchical } \\
\text { relationships }\end{array}$ & $\begin{array}{l}\text { They do not consider all } \\
\text { the hierarchical } \\
\text { relationships between the } \\
\text { different classes (they do } \\
\text { not contemplate the } \\
\text { transitivity when } \\
\text { defining), but they do } \\
\text { define some figures or } \\
\text { shapes, recognising their } \\
\text { inclusion in a more } \\
\text { general class (consider the } \\
\text { specialization process } \\
\text { partially) }\end{array}$ & 4 & 1 & 3 & 3 \\
\hline $\begin{array}{l}\text { Profile 3. Use of the } \\
\text { specialization process in } \\
\text { the definitions that entail } \\
\text { the transitivity of the } \\
\text { hierarchical relationships }\end{array}$ & $\begin{array}{l}\text { They reflect the } \\
\text { specialization process in } \\
\text { the definition of the } \\
\text { geometric figures and take } \\
\text { into account the } \\
\text { hierarchical relationships } \\
\text { (adding properties to the } \\
\text { figures or shapes of a class } \\
\text { to generate a more specific } \\
\text { class and considering the } \\
\text { transitivity) }\end{array}$ & 0 & 4 & 1 & 4 \\
\hline Other & $\begin{array}{l}\text { They do not provide a } \\
\text { coherent response to the } \\
\text { task }\end{array}$ & 1 & 0 & 2 & 15 \\
\hline TOTAL & & 5 & $\begin{array}{l}12 \\
28\end{array}$ & 11 & 28 \\
\hline
\end{tabular}

\section{Profile 1. Without using the specialization process in the definitions}

In this profile, preservice teachers do not recognise the process of generating subclasses, that is to say, by adding properties to the definition of figures or shapes of a class, a more specific class (subclass) is generated. The preservice teachers in this profile do not take into account in any case the 
process of specialization of the definitions, so they do not manage to consider the transitivity between the hierarchical relationships. For example, the EM10 preservice teacher, on task 1b, Rhomboid ? Rhombus ? Square, indicated,

Rhomboid: A figure of four sides that do not form right angles, of which the opposites are equal, and the contiguous ones are unequal

Rhombus: A geometric figure of four equal sides that do not form right angles.

Square: A figure that has four equal sides that form four right angles.

By indicating that no right angles are formed in the definition of rhombus, the individual eliminates the possibility of including squares as a subclass of the rhombus. In the same way, when defining the rhomboid, indicating that the contiguous sides are different, the preservice teacher eliminates the possibility that the rhomboids can be considered a subclass of the rhomboids. Finally, when defining rhomboid as quadrilaterals that do not form right angles, he is excluding the possibility of squares as a subclass, not recognising the transitivity in the hierarchical relationships.

Some preservice teachers in this profile provide incorrect definitions that prevent them from including the figures or shapes in more general classes. For example, in task 1d, Prism $->$ Parallelepiped $\rightarrow$ Cube, preservice teacher EM9 indicated:

- The cube is a regular prism of square faces

- The parallelepiped is a prism where the bases and side faces are parallel

- The prism is a polyhedron with two faces that are parallel and equal, formed by base faces and lateral faces

This preservice teacher defines prism and parallelepiped incorrectly by not indicating how the lateral faces of the prism are and that in the parallelepipeds, all faces are parallelograms. However, he defines the cube correctly, although without using the specialization process, by not indicating what is meant by a regular prism. In this way, having defined prism and parallelepiped incorrectly, it is not possible to establish hierarchical relationships between these shapes (non-transitivity). 


\section{Profile 2. Partial use of the specialization process in the definitions that entail the non-transitivity of the hierarchical relationships}

The preservice teachers in this profile define the figures and shapes considering only some of the conditions of inclusion, showing a partial understanding of the specialization process. The lack of understanding of the transitivity of the hierarchical relationships is manifested when they define some figures or shapes using attributes of the prototypical examples, but not all the necessary attributes. For example, in task 1c, Quadrilateral -> Kite -> Rhombus -> Square, preservice teacher EM24 answered:

As in level 3, we know that the student can make hierarchical classifications (relate properties, define figures with necessary and sufficient properties), the student would do it as follows (stands out for the exclusive property of each figure):

- Quadrilateral: A geometric figure of four sides.

- Kite: A non-regular figure whose sides are congruent two by two.

- Rhombus: A figure which sides are equal, and its angles are congruent two by two.

- Square: A figure of four sides, and the sides and angles are congruent

This student defined some figures incorrectly (for example, in the definition of a kite, by not including that the congruent sides must be the adjacent ones) and did not consider the specialization of the definitions in all cases and, consequently, the transitivity of the definitions (e.g. defining kite as a non-regular figure, what exclude to the squares). Of the three hierarchical relationships established in task $1 \mathrm{c}$, the only one that takes it into account is the hierarchical relationship between the rhombus and the square when defining square by changing the condition angles are congruent two by two, for the angles are congruent.

Another example of this feature is in task 1d, Prism -> Parallelepiped $>$ Cube, to which preservice teacher EM16 stated: 
Prism: It is an irregular polyhedron that consists of two equal and parallel faces called bases, and lateral faces that are parallelograms.

Parallelepiped: A six-sided polyhedron, in which all faces are parallelograms, parallel, and equal two by two.

Cube: A type of regular parallelepiped, it is a polyhedron bounded by six congruent square faces.

This preservice teacher defines prism incorrectly by describing it as an irregular polyhedron, so it excludes the possibility of including some parallelepipeds and cubes in this more general class. However, he defines parallelepiped correctly, but without using the specialization of the prism definition; and he/she defines cube correctly using the specialization process of the definition of the parallelepiped, although he/she provides additional information by indicating that it is a polyhedron, establishing the hierarchical relationship of the cube in the parallelepipeds.

In this profile, some students include irrelevant information in the definition of a figure. For example, in task 1b, Rhomboid -> Rhombus -> Square, preservice teacher EM8 defined the quadrilateral as having four edges and four vertices:

The student would say that they are all quadrilaterals because they have four edges and four vertices, but that the rhomboid has equal sides two by two and equal angles two by two, the rhombus has four equal sides but different angles two by two, and that the square has all equal sides and angles.

In this example, the preservice teacher defines quadrilateral as having four sides and four vertices, adding that the four-sided figure has four vertices, using irrelevant information. Moreover, this preservice teacher considers the hierarchical relationship between the rhomboids and the rhombus; however, he does not consider the hierarchical relationship between the rhomboid and the square, since he defines the rhomboid as having the different angles two by two, thus excluding the squares.

Thus, in the same answer given by a preservice teacher, we can find these three characteristics: (i) not considering the two hierarchical relationships between the different classes (not contemplating the transitivity) but (ii) defining some figures or shapes, recognising their inclusion in a more general class (considering the specialization process partially), and (iii) incorrectly 
defining some figures or shapes only using some of the properties of the prototypical examples.

For example, in task 1a, Trapezium $\rightarrow$ Isosceles Trapezium $\rightarrow$ Rectangle $\rightarrow$ Square, preservice teacher EM2 indicated:

As it is at level 3, he can analyse the properties of the geometric figures giving the right and necessary indications, relating the properties to each other:

- the trapezium is a quadrilateral with only two parallel sides.

- $\quad$ the isosceles trapezium is a quadrilateral with two equal angles two by two.

- $\quad$ the rectangle is a quadrilateral with all right angles.

- $\quad$ the square is a quadrilateral with all equal sides and all right angles.

When defining trapezium as a quadrilateral with only two parallel sides (partitive definition), this preservice teacher excludes the possibility of considering the rest of parallelograms (rectangle and square) as subclasses and, therefore, he does not take into account the trapezium relationship transitivity. When defining isosceles trapezium as a quadrilateral with [two] equal angles two by two, he seems to be using some properties of the prototypical figure, but not all. Finally, the definitions and the hierarchical relationship of the squares in the rectangles are adequately indicated, but reflecting judgments supported on the attributes of the prototypical figures (rectangles as a quadrilateral with all right angles and squares as a quadrilateral with equal sides and all right angles) and evidencing the characteristic of the specialization between the rectangle and the square (adding properties implies generating subclasses: the square is a rectangle with equal sides).

\section{Profile 3. Use of the specialization process in the definitions that entail the transitivity of the hierarchical relationships}

The preservice teachers in this profile define the geometric figures and shapes considering, in all cases, the specialization process, adding attributes to the more general class to generate the definitions of the more specific classes, which entails the transitivity of the hierarchical relationships. For example, that the square is a rhombus, and the rhombus is a rhomboid. However, in some 
cases, they provide redundant information to define figures and geometric shapes. For example, in task 1b, Rhomboid -> Rhombus -> Square, preservice teacher EM17 states:

- Rhomboid: A parallelogram with internal angles less than $180^{\circ}$, and with four parallel sides two by two.

- Rhombus: A rhomboid with four equal sides and perpendicular diagonals.

- Square: A rhombus with four right angles

This preservice teacher adds redundant information in the definition of a rhomboid: a parallelogram with angles less than $180^{\circ}$ and parallel sides two by two. However, he explicitly uses the process of specialization of definitions (a rhombus is a rhomboid that ...; a square is a rhombus that....), showing the transitivity of the hierarchical relationships.

Another example showing the characteristics of this profile is the preservice teacher EM2's answer to task 1d, Prism -> Parallelepiped -> Cube. EM2 stated:

- $\quad$ The cube is an example of a parallelepiped with all equal faces and all right angles

- $\quad$ The parallelepiped is an example of a prism with six faces that are parallel parallelograms and equal two by two.

- $\quad$ The prism is a polyhedron with parallel bases, which sides are parallelograms

The preservice teacher defines the three geometric shapes correctly using the specialization process when defining cube as an example of parallelepiped and parallelepiped as an example of a prism, adding the attributes that generate the subclasses, showing the transitivity of the hierarchical relationships. When defining the prism, this student uses the term sides, but we understand he refers to faces, which is the correct definition. Also, by indicating that it has parallel bases and their faces are parallelograms, although not suggesting that their bases are equal, it can only be a prism. 


\section{Differences in anticipating answers in tasks of defining quadrilaterals and prisms with hierarchical conditions}

The organisation of answers across the three profiles has shown that some preservice teachers were assigned to different profiles in the case of quadrilaterals and prisms. This data points the difference in the way in which teachers understood the processes of specialization/generalization and transitivity in different geometric domains (quadrilaterals and prisms). Table 2 shows the assignment of preservice teachers in each profile.

\section{Table 2}

Assignment of preservice teachers in the profiles of anticipating students' answers in tasks of defining considering hierarchical relationships $(n=28)$

\begin{tabular}{|c|c|c|c|c|c|c|}
\hline & \multicolumn{4}{|c|}{ Geometric figures } & \multicolumn{2}{|c|}{ Geometric shapes } \\
\hline & $\mathbf{1 a}$ & $1 b$ & 1c & $\mathbf{n}$ & & $\mathbf{n}$ \\
\hline Profile 1 & - & $\begin{array}{c}\text { EM6, EM8, } \\
\text { EM10, } \\
\text { EM12, } \\
\text { EM13, } \\
\text { EM14, } \\
\text { EM16 }(n=7)\end{array}$ & $\begin{array}{c}\text { EM18, } \\
\text { EM20, } \\
\text { EM22, } \\
\text { EM25, } \\
\text { EM27 }(n=5)\end{array}$ & 12 & $\begin{array}{c}\text { EM1, EM9, } \\
\text { EM10, EM13, } \\
\text { EM14, EM18 }\end{array}$ & 6 \\
\hline Profile 2 & $\begin{array}{c}\text { EM2, EM3, } \\
\text { EM4, EM5 } \\
(n=4)\end{array}$ & $\operatorname{EM} 9(n=1)$ & $\begin{array}{c}\text { EM21, } \\
\text { EM24, } \\
\text { EM28 }(n=3)\end{array}$ & 8 & $\begin{array}{c}\text { EM16, EM17, } \\
\text { EM25 }\end{array}$ & 3 \\
\hline Profile 3 & - & $\begin{array}{c}\text { EM7, } \\
\text { EM11, } \\
\text { EM15, } \\
\text { EM17 }(n=4)\end{array}$ & $\operatorname{EM} 23(n=1)$ & 5 & $\begin{array}{c}\text { EM2, EM3, } \\
\text { EM15, EM25 }\end{array}$ & 4 \\
\hline Other & $\operatorname{EM} 1(n=1)$ & - & $\begin{array}{c}\text { EM19, } \\
\text { EM26 }(n=2)\end{array}$ & 3 & $\begin{array}{c}\text { EM4, EM5, } \\
\text { EM6, EM7, } \\
\text { EM8, EM11, } \\
\text { EM12, EM19, } \\
\text { EM20, EM21, } \\
\text { EM22, EM23, } \\
\text { EM24, EM27, } \\
\text { EM28 }\end{array}$ & 15 \\
\hline TOTAL & 5 & 12 & 11 & 28 & 28 & 28 \\
\hline
\end{tabular}


Table 3 shows the changes in profile assignment considering the context of quadrilaterals/parallelograms and prisms.

\section{Table 3}

Profile assignment changes considering the context of figures and geometric shapes $(n=22)$

\begin{tabular}{llll}
\hline Quadrilaterals & Prisms & Preservice teachers & N \\
\hline From Profile 1 & To Profile 2 & EM16 & 1 \\
& To Profile 3 & EM25 & 1 \\
& To Others & EM6, EM8, EM10, EM12, EM20, & 6 \\
From Profile 2 & To Profile 3 & EM2, EM3 & 2 \\
& To Profile 1 & EM9 & 3 \\
From Profile 3 & To Profile 2 & EM17 & 5 \\
& To Profile 1 & - & 1 \\
& To Others & EM7, EM11, EM23 & 0 \\
From Others & Profile 1 & EM1 & 1 \\
& Profile 2 & - & 1 \\
TOTAL & Profile 3 & EM26 & 0 \\
\hline
\end{tabular}

Table 4 shows the six preservice teachers who answered by remaining in the same profile on quadrilateral and prism tasks. Of these six preservice teachers, four were in profile 1 , one in profile 3 , and one in Others. The other twenty-two were placed in different profiles (Table 3). 


\section{Table 4}

They keep in the same profile in the context of figures and geometric shapes $(n=6)$

\begin{tabular}{llc}
\hline \multicolumn{1}{c}{$\begin{array}{c}\text { Quadrilaterals and } \\
\text { Prisms }\end{array}$} & Preservice teachers & n \\
\hline In Profile 1 & EM10, EM13, EM14, EM18 & 4 \\
In Profile 2 & - & 0 \\
In Profile 3 & EM15 & 1 \\
In Others & EM19 & 1 \\
TOTAL & & $\mathbf{6}$ \\
\hline
\end{tabular}

\section{CONCLUSIONS}

The objective of this study was to characterise the curricular reasoning processes of preservice primary teachers when they anticipate correct answers in tasks of defining quadrilaterals and prisms, considering some hierarchical relationships as a skill linked to curricular noticing. The preservice teachers participated in a teaching experiment to develop the curricular noticing as an aspect of professional noticing, considering the connection between the geometric thinking of primary school students and what the instructional task may require to the solver. At the end of the teaching experiment, the preservice primary teachers responded to two tasks: anticipating definitions of geometric figures and geometric shapes, fulfilling some hierarchical relationships (relationship between defining geometric figures/geometric shapes and hierarchical relationships). Specifically, in this task, the preservice teachers were requested to anticipate definitions of quadrilaterals and prisms considering some hierarchical conditions, considering the processes of the specialization of the definitions and the transitivity of the hierarchical relationships.

The results show three preservice teachers' curricular reasoning profiles and some variability in their reasoning processes in the domain of quadrilaterals and prisms. These characteristics of the preservice teachers' curricular reasoning generate two ideas. Firstly, on the preservice teachers' understanding of the relationship between defining and classifying. Secondly, on the relationship between geometry knowledge and the ability to determine the potential of some teaching activities to support the development of 
geometric thinking (characteristics of preservice teachers' curricular reasoning).

\section{The preservice teachers' understanding of the relationship between defining and classifying}

The ideas of specialization of the definitions and the transitivity of the hierarchical relationships are key in the understanding of the relationship between the processes of defining and classifying. In the proposed tasks, the preservice teachers should consider both the specialization process when defining different quadrilaterals and prisms, and the transitivity of the hierarchical relationships under the conditions indicated. The specialization process makes it possible to understand how, by adding properties to the definition of figures (quadrilaterals or prisms), subclasses of a more general class are generated. Moreover, define to reflect two (or more) hierarchical relationships is the second key aspect that preservice primary teachers should grasp. The transitivity of the hierarchical relationships is linked to the generalization process of the definitions, which allows including a figure (A) within a class (B) and at the same time, including this class within another more general class (C) (Figure 2).

\section{Figure 2}

Graph of the relationship between specialization and transitivity

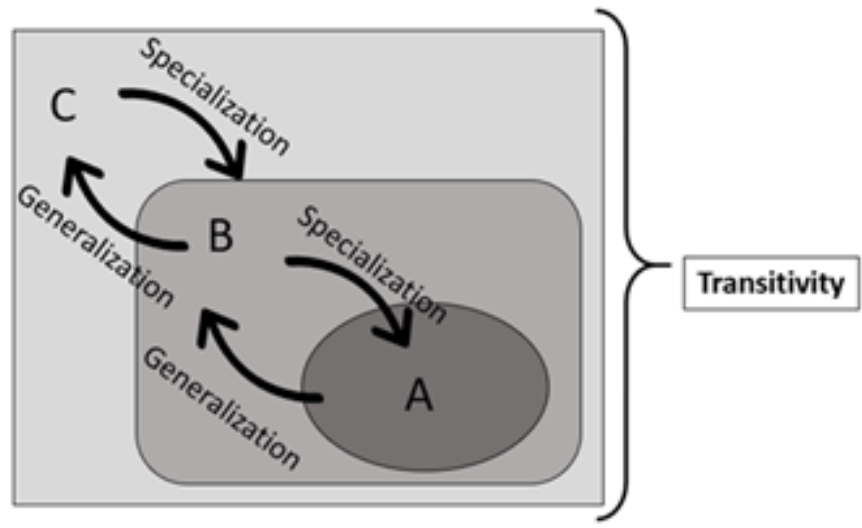


In this way, the preservice primary teachers' apprehension of the specialization and transitivity processes is key in interpreting what instructional tasks may require to the primary students. Understanding the conceptual relationships between the figures, dismissing the misconceptions generated by the prototypical examples, as it has been observed in the preservice teachers in profile 3 (Use of the specialization process in the definitions that entail the transitivity of the hierarchical relationships) (Hershkowitz, 1990), seems to be a necessary condition for them to be able to analyse the potential of geometry tasks in primary education. Profiles 1 and 2 can be interpreted as if some preservice teachers were influenced by prototypical figures and shapes by defining them based on the hierarchical relationship (Hershkowitz, 1990), which limits their ability to anticipate primary education students' answers to tasks aimed at developing the understanding of the relationship between defining and classifying.

\section{Characteristics of curricular reasoning in preservice teachers}

Preservice primary teachers' curricular reasoning indicates ways of thinking about instructional tasks and, specifically, what these tasks may require to the solvers in order to determining their validity in supporting learning. An aspect of preservice teachers' curricular reasoning is manifested when anticipating students' answers to activities reflecting characteristics of students' understanding. In this study, the specialization in defining and the transitivity between the hierarchical relationships have been seen as key aspects that the teachers must consider analysing the potential of the geometrical classification tasks of geometrical objects. Anticipating students' answers can be considered a skill in the process of interpreting instructional tasks as part of curricular noticing (Amador et al., 2017; Llinares et al, 2016). Interpreting the instructional task involves identifying the mathematical content in the task and seeing what the task may require to the resolutor. We have identified three preservice teachers' curricular reasoning profiles that show the interaction between mathematic knowledge, knowledge of students' learning and knowledge of mathematics teaching in the same way in how preservice teaches make teaching decision considering students' mathematical reasoning (Buforn, Llinares, Fernández, Coles, and Brown, 2020)

On the other hand, the results indicate differences in how preservice teachers use the specialisation process and the transitivity of hierarchical relationships between quadrilaterals and prisms. Of the three tasks about quadrilaterals that are parallelograms (rhomboid, rhombus, and square) they 
have been less successful in applying the specialization process. In these tasks, they have mostly generated non-hierarchical definitions (see Profile 1 of Table 2 , students of version 1a). One possible explanation of this finding is that these figures are the most used to exemplify the concept of quadrilateral, and the preservice teachers could have prototypical examples that hinder the analytical reasoning need to consider the hierarchical relationships. In addition, the partitive definitions have been generated mainly between geometrical objects in the first hierarchical relationship (for example, in task 1b, Rhomboid -> Rhombus; in task 1d, Prism $\rightarrow$ Parallelepiped). This finding seems to indicate the difficulty that the generalization process entails (eliminating certain properties or replacing them with more general ones) when the concepts have already been acquired (a posteriori classification) (de Villier, 1994) (Figure 3).

Other difference between geometrical figures and shapes is that while in the definitions of geometric figures only three of the 28 preservice teachers are in Others (incorrect or inconsistent definitions), in the definitions of geometric shapes, there are 15 preservice teachers (Table 2). In the task of defining geometric shapes (task 1d), many preservice teachers gave definitions in which attributes were missing and they were considered incorrect. On the other hand, although giving correct definitions, some preservice teachers included additional information which was redundant. Furthermore, the results in defining geometric figures have shown that some preservice teachers used excluding attributes such as indicating that prism is an irregular polyhedra or that prism has rectangular side faces. However, when defining geometric figures, there were more preservice teachers using two or three partitive definitions. These differences between figures and geometric shapes when preservice teachers define the geometrical objects considering inclusive relationships seem indicate differences in how preservice teachers know the geometrical objects. This finding seem to indicate that it is not the same to attend to the parts of a 2D figure (sides, vertices, angles, symmetry) as attending to the attributes of geometric shapes ((Markopoulos, 2003; Pittalis \& Christou, 2010). Globally considered, the findings of this study indicate that is necessary to increase the use of similar tasks to those used in this research, especially with geometric shapes, in teacher education programs in order to enhance preservice teachers' curricular reasoning.

\section{AUTHORSHIP CONTRIBUTIONS STATEMENTS}

MB, MM, and SLl conceived the presented idea. MB, MM, and SLl developed the theory. MB, MM, and SLl adapted the methodology to this 
context, created the models, performed the activities, and collected the data. MB, MM, and SLl analysed the data. All authors actively participated in the discussion of the results, reviewed, and approved the final version of the work.

\section{DATA AVAILABILITY STATEMENT}

Data supporting the results of this study will be made available by the corresponding author, upon reasonable request.

\section{ACKNOWLEDGEMENTS}

Work carried out with the support of the project Reference: PID2020116514GB-I00, Agencia Estatal de Investigación, Ministerio de Ciencia e Innovación, Spain, and PROMETEO 2017-135, Generalitat Valencia, Spain, and project coReflect@maths, 2019-1-DE01-KA203-004947).

\section{REFERENCES}

Amador, J., Males, L., Earnest, D., \& Dietiker, L. (2017). Curricular Noticing: Theory on and Practice of Teachers' Curricular Use. In E. Schak; M. Fisher \& J. Wilhelm, (Eds.), Teacher Noticing: Bridging and Broadening Perspectives, Contexts and Frameworks (pp. 427443). Springer.

Bernabeu, M., Llinares, S. (2017). Comprensión figuras geométricas en niños de 6-9 años. Educación Matemática, 29(2), 9-35. http://doi.org/10.24844/EM2902.01

Breyfogle, M. L., Roth McDuffie, A., \& Wohlhuter, K. A. (2010). Developing curricular reasoning for grades pre-K-12 mathematics instruction. In B. Reys, R. E. Reys, \& R. Rubenstein (Eds.), Mathematics curriculum: Issues, trends, and future directions (pp. 307-320). National Council of Teachers of Mathematics.

Brunheira, L. \& da Ponte, P. (2019). From the classification of quadrilaterals to the classification of prisms: An experiment with prospective teachers. Journal of Mathematical Behavior, 53, 65-80. https://doi.org/10.1016/j.jmathb.2018.06.004 
Buforn, A., Llinares, S., Fernández, C., Coles, A., Brown, L. (2020). Preservice teachers' knowledge of the unitizing process in recognizing students' reasoning to propose teaching decisions. International Journal of Mathematical Education in Science and Technology, https://doi.org/10.1080/0020739X.2020.1777333

De Villiers, M. (1994). The role and function of a hierarchical classification of quadrilaterals. For the Learning of Mathematics, 14(1), 11-18.

Dietiker, L., Males, J., Amador, J., \& Earnest, D. (2018). Research Commentary: Curricular Noticing: A Framework to Describe Teachers' Interactions with Curriculum Materials. Journal for Research in Mathematics Education, 49 (5), 521-532. https://doi.org/10.5951/jresematheduc.49.5.0521

Fernandez, C., Sánchez-matamoros. G., Valls, J., Callejor, M.L. (2018). Noticing students' mathematical thinking: characterizatrion, development and contexts. AIEM. Avances de Investigación en Educación Matemática, 13, 39-61.

Fischbein, E. (1993). The theory of figural concepts. Educational studies in mathematics, 24(2), 139-162. https://doi.org/10.1007/BF01273689

Fujita, T. (2012). Learners' level of understanding of the inclusion relations of quadrilaterals and prototype phenomenon. The Journal of Mathematical Behavior, 31(1), 60-72. http://doi.org/10.1016/j.jmathb.2011.08.003

Fujita, T. \& Jones, K. (2007). Learners' understanding of the definitions and hierarchical classification of quadrilaterals: Towards a theoretical framing. Research in Mathematics Education, 9(1), 3-20. https://doi.org/10.1080/14794800008520167

Gueudet, G. (2019). Studying Teachers' Documentation Work: Emergence of a Theoretical Approach. In L. Trouche, G. Gueudet, \& B. Pepin (Eds.), The 'Resource' Approach to Mathematics Education (pp. 1742). Springer.

Hershkowitz, R. (1990). Psychological aspects of learning geometry. In Nesher \& Kilpatrick (Eds.), Mathematics and cognition (pp. 70-95). Cambridge University Press.

Jones, K. \& Tzekaki, M. (2016). Research on teaching and learning geometry. In A. Gutierrez, G. Leader, \& P. Boero (Eds.), The second Handbook 
of research on the psychology of mathematics education (pp. 109149). Sense.

Lehrer, R., Slovin, H., \& Dougherty, B. (2014). Developing Essential Understanding of Geometry and Measurement for Teaching Mathematics in Grades 3-5. NCTM.

Llinares, S., Fernández, C., Sánchez-Matamoros, G. (2016). Changes in how prospective teachers anticipate secondary students' answers. Eurasia Journal of Mathematics, Science \& Technology Education, 12(8), 2155-2170. http://doi.org/10.12973/eurasia.2016.1295a

Markopoulos, C. (2003). Teaching and learning of solids with the use of technological tools. Unpublished Doctoral Dissertation, University of Patra, Greece.

Pittalis, M. \& Christou, C. (2010). Types of reasoning in 3D geometry thinking and their relation with spatial ability. Educational Studies in mathematics, 75(2), 191-212. https://doi.org/10.1007/s10649-010$\underline{9251-8}$

Sinclair, N., Bussi, M. G. B., de Villiers, M., Jones, K., Kortenkamp, U., Leung, A., \& Owens, K. (2016). Recent research on geometry education: An ICME-13 survey team report. ZDM, 48(5), 691-719. https://doi.org/10.1007/s11858-016-0796-6

Usiskin, Z. \& Griffin, G. (2008). The classification of Quadrilaterals. A Study of definition. IAP.

Remillard, J, (2019). Teacher'Use of mathematics Resources: A Look Across Cultural Boundaries. In L. Trouche, G. Gueudet, \& B. Pepin (Eds.), The 'Resource' Approach to Mathematics Education, (pp. 173-194). Springer.

Wilson, S., M., Shulman, L. \& Richert, A. E. (1987). '150 different ways of knowing: Representations of knowledge in teaching. In J. Calderhead (ed.), Exploring Teachers' Thinking, (104-124). Casssell

van Hiele, P. M. (1986). Structure and insight: A theory of mathematics education. Academic Press. 